\title{
PERANCANGAN MESIN PEMBERSIH USUS UNTUK MENINGKATKAN PRODUKTIVITAS DI UKM KECAMATAN BANDAR KABUPATEN BATANG
}

\author{
Firman Ardiansyah Ekoanindyo ${ }^{1)}$, Antoni Yohanes $^{2)}$, Rieska Ernawati ${ }^{3)}$ \\ ${ }^{1.2}$ Program Studi Teknik Industri, Fakultas Teknik Universitas Stikubank Semarang \\ ${ }^{3}$ Program Studi Teknik Industri, Fakultas Teknik dan Rekayasa Universitas Slamet Sri Kendal \\ e-mail: firman@edu.unisbank.ac.id ${ }^{1)}$, antoni@edu.unisbank.ac.id ${ }^{2)}$,ernawatirieska@gmail.com ${ }^{3)}$
}

\begin{abstract}
Abstrak
Abstrak: Banyaknya permintaan usus ayam, menjadikan UKM ayam potong untuk memenuhi permintaan tersebut. Permasalahan yang timbul ketika proses pembersihan usus ayam masih menggunakan tangan/manual dan sering kali usus terpelintir pada saat pembersihan sehingga menyebabkan kecacatan usus. Akibat kejadian tersebut, proses pembersihan usus akan terganggu. Waktu yang digunakan untuk pembersihan usus ayam satu kilogram adalah enam puluh menit. Berdasarkan permasalahan pada UKM kecamatan Bandar Kabupaten Batang, diperlukan penelitian yang bertujuan untuk merancang mesin pembersih usus ayam dengan memperhatikan aspek ergonomi agar dapat meningkatkan produktifitas pekerja. Dengan mesin semi otomastis ini diharapkan dapat membantu UKM pemotong ayam meningkatkan produktifitasnya Dengan adanya mesin semi otomatis ini proses pembersihan usus setiap satu kilogram yang memerlukan waktu enam puluh menit, dengan adanya mesin semi otomatis proses pembersihan usus setiap satu kilogram menjadi tiga puluh menit. Dalam perancangan ini memperhatikan aspek ahthropometri tenaga kerja serta persentil.
\end{abstract}

Kata kunci: peracangan mesin semi otomatis, produktifitas, anthtropometri dan ergonomi

Abstract: The high demand for chicken intestines has made chicken UKM to meet this demand. Problems that arise when the process of cleaning chicken intestines is still using hand / manual and often the intestines are twisted during cleaning, causing intestinal defects. As a result of this incident, the colon cleansing process will be disrupted. The time spent cleaning one kilogram of chicken intestines is sixty minutes. Based on the problems in UKM in Bandar sub-district, Batang regency, a research is needed which aims to design a chicken intestine cleaning machine with due regard to ergonomic aspects in order to increase worker productivity. With this semi-automatic machine, it is hoped that it can help chicken-cutting UKM to increase their productivity. With this semi-automatic machine, the process of cleaning the intestines every one kilo gram takes sixty minutes, with the semiautomatic machine the process of cleansing the intestines every one kilo gram becomes thirty minutes. In this design, we pay attention to the aspects of labor and percentile ahthropometry.

Keywords: semi-automatic machine design, productivity, anthropometry and ergonomics

\section{PENDAHULUAN}

Dalam usaha pemotongan ayam, jeroan ayam tidak dibuang begitu saja. Usus merupakan salah satu jeroan ayam yang sering dibuat menu makanan berat maupun makanan ringan, seperti osengoseng usus, sate usus, usus goring / usus crispy dan masih banyak olahan makanan dari usus ayam (Taqori, 2018).
Banyaknya permintaan usus ayam, menjadikan UKM ayam potong untuk memenuhi permintaan tersebut. Permasalahan yang timbul ketika proses pembersihan usus ayam masih menggunakan tangan/manual dan sering kali usus terpelintir pada saat pembersihan sehinga menyebabkan kecacatan usus. Akibat kejadian tersebut, proses pembersihan usus akan terganggu. Waktu 
yang digunakan untuk pembersihan usus ayam satu kilogram adalah enam puluh menit.

Menurut Tommy (2018), perancangan alat pembersih dan pemotong usus menggunakan metode benchmarking bertujuan agar pemotongan dan pembersihan usus lebih cepat. Alat teknologi tepat guna pencuci tembolok, usus, ampela dan selaput ampela dapat meningkatkan indeks (Moses Laksono Singgih dan Mera Kariana, 2008).

Penggunakan alat menbel pada awalnya dengan alat manual dan sederhana, setelah digantikan dengan alat mesin dapat menghasilkan perubahan terhadap kecepatan kerja. dengan selisih waktu kerja dengan mesin baru. (Jaka Purnama dan Abdul Haris H.A, 2016). Putri Rachmawati (2019) pada percobaan yang telah dilakukan pada mesin perajang singkong yang telah dilakukan rancang bangun dengan aspek ergonomik memiliki tingkat produktivitas sebesar empat puluh $\mathrm{kg} / \mathrm{jam}$.

Berdasarkan permasalahan pada UKM kecamatan Bandar Kabupaten Batang, diperlukan penelitian yang bertujuan merancang mesin pembersih usus ayam dengan memperhatikan aspek ergonomi untuk meningkatkan produktifitas pekerja.

\section{METODE PENELITIAN}

\section{Lokasi dan Objek Penelitian}

Lokasi penelitian di UKM pemotong ayam pasar desa Bandar di Kecamatan Batang.

\section{Populasi dan Sampel}

Sampel sebanyak 15 pekerja usia antara 20 sampai dengan 30 tahun.

\section{Diagram Alir}

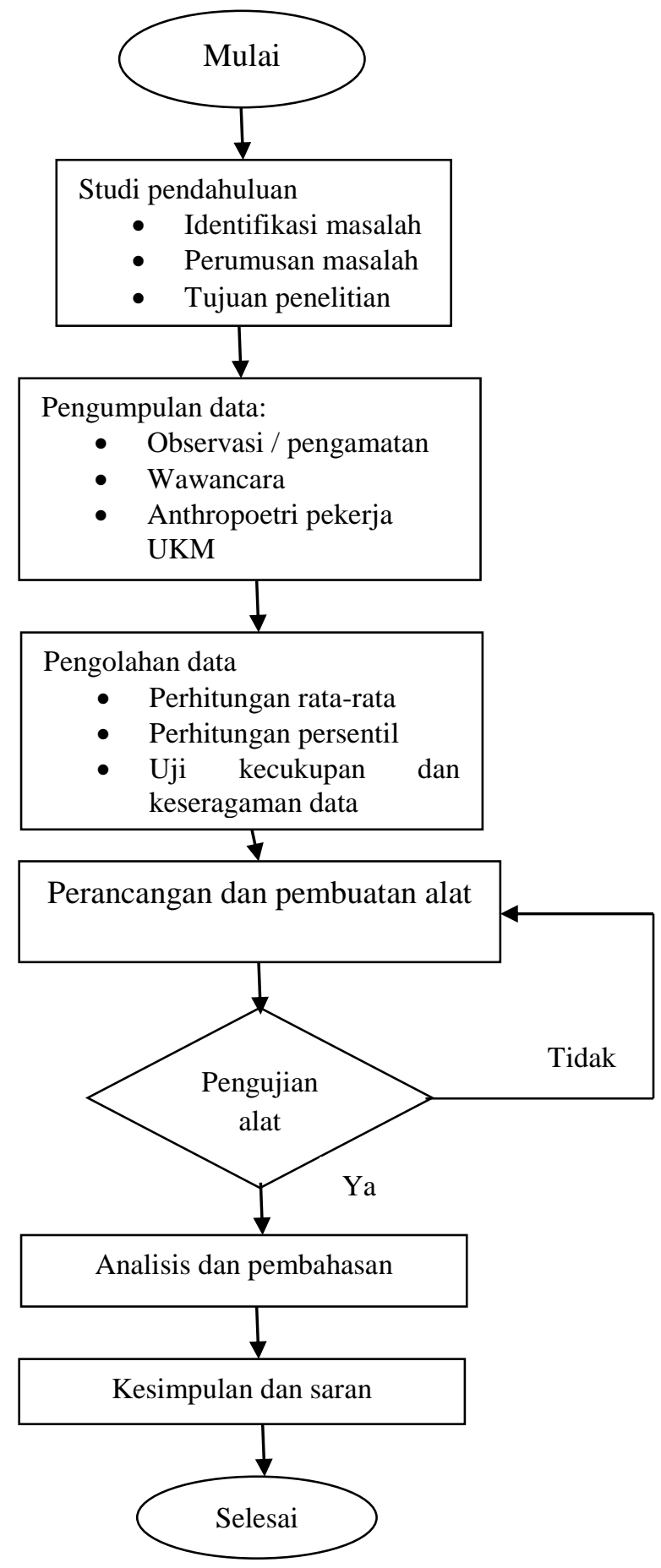

Gambar 1. Diagram alir

\section{HASIL DAN PEMBAHASAN}

Data pengukuran anthropometri pekerja di UKM potong ayam yang dipakai tinggi pinggul, jangkauan tangan, dan lebar bahu. Hasilnya dapat dilihat pada tabel berikut : 
Tabel 1. Data Anthoprometri Pekerja

\begin{tabular}{|c|c|c|c|c|c|}
\hline No & Dama & Tenis & In & Ikt & Ib \\
\hline 1 & Selanet & I & 82 & 68 & 50 \\
\hline 2 & Siti & $\bar{p}$ & 75 & 67 & 47 \\
\hline 3 & Solikin & I & 83 & 70 & 52 \\
\hline 4 & Iurriati. & p & 74 & 65 & 45 \\
\hline 5 & Iastri. & P & 74 & 66 & 46 \\
\hline 6 & Ag45 & I & 80 & 67 & 50 \\
\hline 7 & Yati & P & 73 & 64 & 44 \\
\hline 8 & Yanti & $\bar{p}$ & 75 & 67 & 47 \\
\hline 9 & Adi. & I & 83 & 71 & 53 \\
\hline 10 & Wavan & I & 82 & 69 & 51 \\
\hline 11 & Restr & I & 80 & 67 & 52 \\
\hline 12 & Disa & P & 71 & 64 & 46 \\
\hline 13 & Dilla & $\bar{P}$ & 73 & 67 & 49 \\
\hline 14 & Iyas & $\bar{P}$ & 73 & 66 & 50 \\
\hline 15 & Heri. & I & 84 & 70 & 53 \\
\hline$\sum X$ & & & 1162 & 1008 & 735 \\
\hline$\sum \lambda$ & & & 77,466 & 67,2 & 49 \\
\hline
\end{tabular}

\section{Uji Kecukupan Data}

Dapat dilakukan dengan :

$$
N^{\prime}=\left[\frac{k / s \sqrt{N \sum x^{2}-\left(\sum x\right)^{2}}}{\sum^{\prime} x}\right]^{2}
$$

Hasil uji kecukupan data dapat dilihat tabel berikut ini :

Tabel 2. Hasil Perhitungan Uji Kecukupan Data

\begin{tabular}{|c|l|c|c|c|}
\hline No & Anthropometri & N & N' & Kesimpulan \\
\hline 1 & Tinggi Pinggul & 15 & 5,2565314119 & $\begin{array}{c}\text { N'< N, Data } \\
\text { cukup }\end{array}$ \\
\hline 2 & $\begin{array}{l}\text { Jangkauan } \\
\text { Tangan }\end{array}$ & 15 & 1,473922652 & $\begin{array}{c}\text { N'< N, Data } \\
\text { cukup }\end{array}$ \\
\hline 3 & Lebar Bahu & 15 & 5,5088157712 & $\begin{array}{l}\text { N'< N, Data } \\
\text { cukup }\end{array}$ \\
\hline
\end{tabular}

\section{Uji Keseragaman Data}

\section{TINGGI PINGGUL}
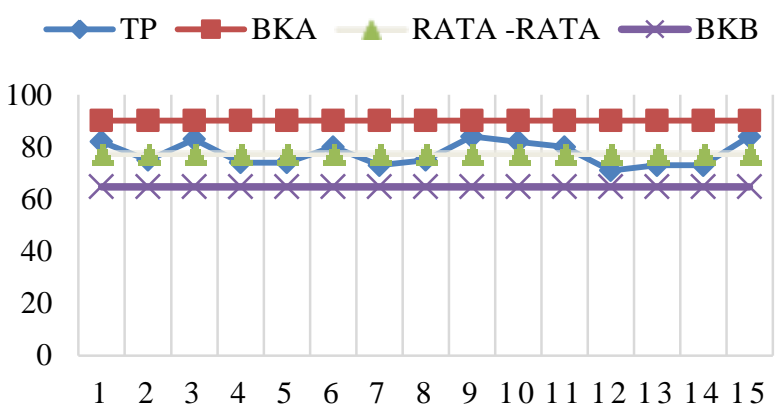

Gambar 2. BKA dan BKB Tinggi Pinggul

\section{JANGKAUAN TANGAN}

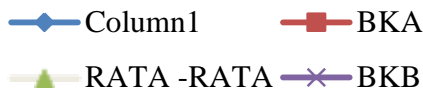

75

70

65

60

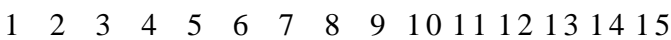

Gambar 3. BKA dan BKB Jangkauan Tangan

\section{LEBAR BAHU}

$\leadsto$ LB $\because$ BKA $\because$ RATA -RATA $*$ BKB

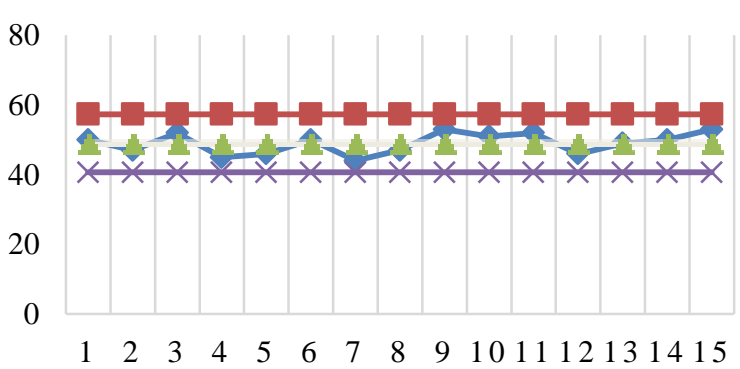

Gambar 4. BKA dan BKB Lebar Bahu 


\section{Persentil}

Dapat dilihat pada tabel di bawah ini :

Tabel 2. Perhitungan Persentil

\begin{tabular}{|c|c|}
\hline Percentil & Perhitungan \\
\hline 1-th & $\bar{X}-2,325 \sigma_{x}$ \\
\hline 2,5-th & $\bar{X}-1,96 \sigma_{x}$ \\
\hline 5-th & $\bar{X}-1,645 \sigma_{x}$ \\
\hline 10-th & $\bar{X}-1,28 \sigma_{x}$ \\
\hline 50-th & $\bar{X}$ \\
\hline 90-th & $\bar{X}+1,28 \sigma_{x}$ \\
\hline 95-th & $\bar{X}+1,645 \sigma_{x}$ \\
\hline 97,5-th & $\bar{X}+1,96 \sigma_{x}$ \\
\hline 99-th & $\bar{X}+2,325 \sigma_{x}$ \\
\hline
\end{tabular}

1. Lebar Pinggul

Perhitungan lebar pinggul merupakan persentase dari orang yang memiliki ukuran pada atau di bawah nilai tersebut. Persentil 5\% populasi akan berada atau dibawah $71 \mathrm{~cm}$, sedangkan untuk 95 menunjukan $95 \%$ akan berada atau di bawah $84 \mathrm{~cm}$.

2. Jangkauan Tangan

Perhitungan jangkauan tangan merupakan persentase dari orang yang memiliki ukuran pada atau dibawah nilai tersebut. Persentil 5\% populasi akan berada atau dibawah $64 \mathrm{~cm}$, sedangkan untuk 95 menunjukan $95 \%$ akan berada atau di bawah $71 \mathrm{~cm}$.

3. Lebar Bahu

Perhitungan lebar bahu merupakan persentase dari orang yang memiliki ukuran pada atau dibawah nilai tersebut. Persentil 5\% populasi akan berada atau dibawah $44 \mathrm{~cm}$, sedangkan untuk 95 menunjukan $95 \%$ akan berada atau dibawah $53 \mathrm{~cm}$.

\section{Model Dan Desain Produk}

Tabel 4. Penentuan Ukuran Desain

\begin{tabular}{|c|c|c|c|c|}
\hline$\overline{\mathrm{N}_{0}}$ & $\begin{array}{l}\text { Thuran } \\
\text { Desin }\end{array}$ & $\begin{array}{c}\text { Data } \\
\text { Anthropometri }\end{array}$ & Ckuran & Ahase \\
\hline 1 & Tinggi mesin & Tingi pinggul & $\begin{array}{c}\text { Persenal } \\
50\end{array}$ & $\begin{array}{l}\text { Pekria yang memilfic tubuh pendek dan } \\
\text { tinggi dapat mengguakan alat yang } \\
\text { dibua: }\end{array}$ \\
\hline 2 & Leter mesil & Lebar balm & $\begin{array}{c}\text { Persenal } \\
95\end{array}$ & 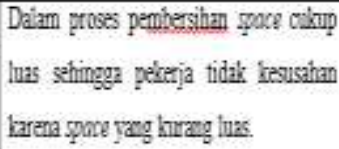 \\
\hline 3 & $\begin{array}{l}\text { Panjang } \\
\text { Mesin }\end{array}$ & $\begin{array}{l}\text { Janghaman } \\
\text { tangan }\end{array}$ & $\begin{array}{c}\text { Persentil } \\
5\end{array}$ & $\begin{array}{l}\text { spara mesill tidak terain panjang } \\
\text { sahingga membatasi ruang gerak pekrja }\end{array}$ \\
\hline
\end{tabular}

Tabel 5. Ukuran Desain Mesin Pembersih Usus Ayam

\begin{tabular}{|c|c|c|}
\hline $\mathrm{N}_{0}$ & Nama Bagginn & Tkuran \\
\hline 1 & Tingginesin - balk & $75 \mathrm{~cm}$ \\
\hline 2 & Lébar mesin & $53 \mathrm{~cm}$ \\
\hline 3 & Panjang mesill & $64 \mathrm{~cm}$ \\
\hline
\end{tabular}

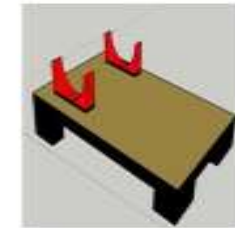

(1)

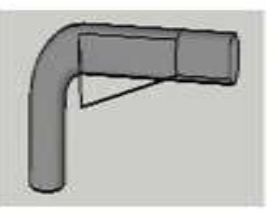

(4)

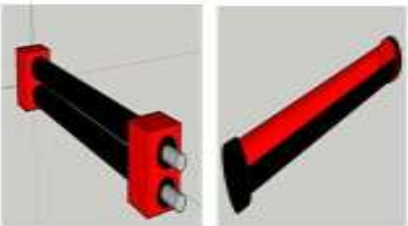

(3)
Gambar 5. Bagian - Bagian Mesin Pembersih Usus Ayam

1. Rangka meja

Fungsi bagian ini digunakan untuk meja atau rangka, dimana smua komponen dirakit diatas shingga menjadi alat pembersih usus ayam. 
2. Rol

Fungsi bagian ini adalah untuk menarik usus ayam serta digunakan sebagai pembersih tahap ke dua.

3. Paralon

Fungsi bagian ini digunakan untuk menaruh usus ayam sebelum dan sesudah pembersihan

4. Pisau

Fungsi bagian ini digunakan untuk merobek usus ayam sehingga usus ayam mudah untuk dibersihkan

5. Busa

Fungsi bagian ini digunkan untuk pembersih usus ayam tahap pertama sebelum masuk ke rol.

6. Mesin pembesih usus ayam semi otomatis

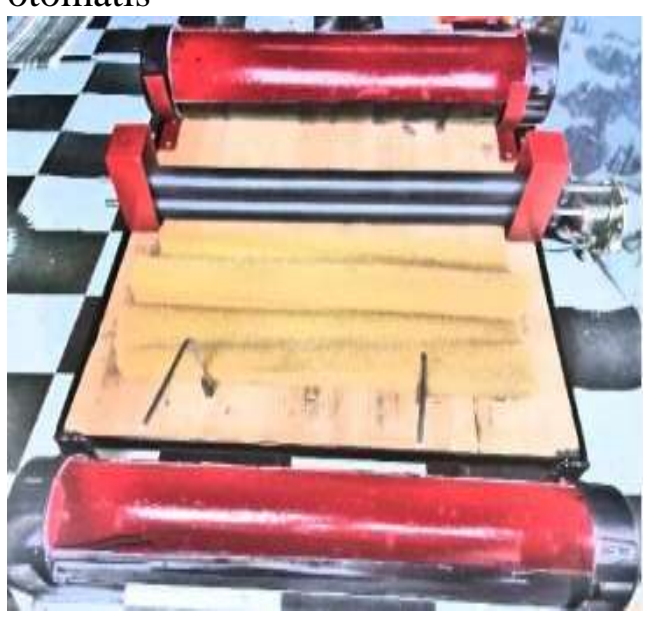

Gambar 6. Mesin Pembersih Usus Ayam

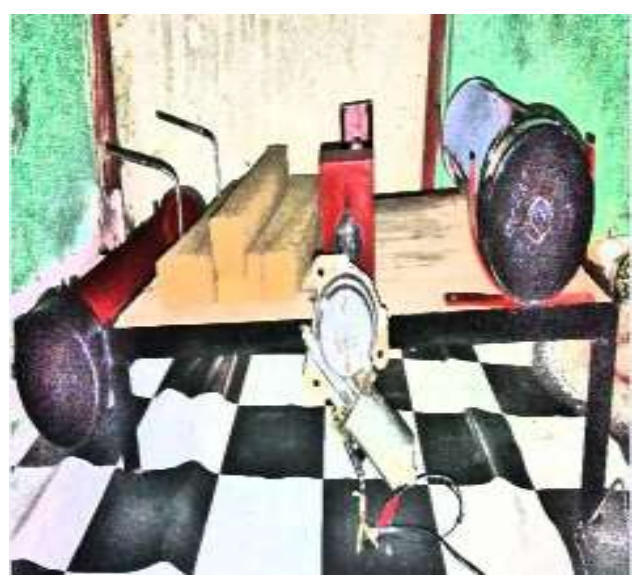

Gambar 7. Gambar Tampak Samping

\section{KESIMPULAN}

Setelah melakukan penelitian pada pekerja di UKM pemotong ayam, maka dapat diambil kesimpulan :

1. Proses pembersihan usus setiap satu kilo gram yang memerlukan waktu enam puluh menit, dengan adanya mesin semi otomatis proses pembersihan usus setiap satu kilo gram menjadi tiga puluh menit.

2. Dengan perancangan alat yang sesuai dengan anthropometri dan ergonomi, pekerja di UKM pemotong ayam Kecamatan Bandar Kabupaten Batang di harapkan menjadi lebih nyaman apabila melakukan pekerjaan dalam waktu lama.

\section{Saran}

Saran - saran yang dapat diberikan berdasarkan pengamatan selama penelitian :

1. Dalam perancangan dan pembuatan produk yang telah dilakukan, masih terdapat kelemahan dan kekurangan baik dari segi desain, maupun fungsinya. Untuk itu diharapkan pada perancangan atau pengembangan produk ini selanjutnya dapat lebih baik lagi dan mengurangi kelemahan dan kekurangan dari desain sebelumnya.

2. Karena keterbatasan waktu dan biaya, untuk penelitian berikutnya dengan konsep yang sama diharapkan dapat lebih menambahkan manfaat yang lebih baik lagi denga inovasi-inovasi yang lebih banyak lagi untuk memudahkan pekerjaan di UKM potong ayam.

\section{DAFTAR PUSTAKA}

Agung Kristanto, Tri Sugiantoro, 2012. Perancangan Ulang Mesin Amplas Kayu Profil Lengkung Untuk Perbaikan Posisi Kerja dan Peningkatan Produktifitas, Jurnal 
Ilmiah Teknik Industri, Vol. 11, No. 2, Des 2012 , pp.(125-135).

Annisa Aulia Sufina Hardima, Lina Dianati Fathimahhayati, Farida Djumiati Sitania, Analisis Postur Kerja Dan Redesign Peralatan Kerja Untuk Mengurangi Risiko Musculoskeletel Disorders Pada Pekerja Pelubangan Plastik Tempe, IEJST (Industrial Engineering Journal of The University of Sarjanawiyata Tamansiswa) Vol. 2 No.1, Juni 2018.

Arda Lonita, Taqori, Peracangan Mesin Pembersih Usus Ayam Semi Otomatis Dengan Menggunakan Metode REBA (Rapid Entire Body Assessment) Untuk Mengurangi Kecatatan Pada Produk, Skripsi, UNISBANK Semarang, 2018.

Desi Natalia, 2016. Perancangan Mesin Pemootng Singkong Untuk Meningkatkan Produktifitas Pembuatan Keripik, Jurnal Teknik Mesin UBL, Vol 4 No. 12016 : 9 12

Hardianto Iridiastadi, Ir. MSIE, Ph.D. Yassierli, Ph.D, 2015, Ergonomi. Buku.

http://lestachi.blogspot.co.id/2013/0 4/perencanaan-dan-perancanganproduk.html Diakses tanggal 27 Januari 2018.

Hasyim Asy'ari, Jatmiko Jatmiko, 2015, Halibona.Djaka. 2013.Identifikasi Resiko Ergonomi Dengan Metode Qec, Nordic Body Map Dan Reba. Unversitas Bina Darma. Palembang

Imam Djati Widodo, 2003, Perencanaan dan Pengembangan Produk, UII Press, Yogyakarta.

Jaka Purnama, Abdul Haris H.A, 2016. Perancangan Mesin Secara
Ergonomi Untuk Meningkatkan Kapasitas Produksi di UKM Mebel, Prosiding Seminar Nasional Sains dan Teknologi Terapan IV.

Liliana Y.P, SuharyoWidagdo, Ahmad Abtokhi, 2007. Pertimbangan Anthropometri Pada Pendisainan. Jurnal. ISSN 1978-0176.

Moses Laksono Singgih, Mera Kariana, 2008. Perancangan Teknologi Tepat GunaUntuk Mengurangi Dampak Lingkungan dan Meningkatkan Pendapatan Rumah Pemotongan Ayam, Prosiding Prosiding Seminar Nasional Manajemen Teknologi VIII.

Nurmianto, Eko, 2004. Ergonomi Konsep Dasar Dan Aplikasi, Prima Printing, Surabaya. Indonesia, Jakarta.

Putri Rachmawati,2019. Rancang Bangun Mesin Perajang Singkong yang Memenuhi Aspek Ergonomis untuk Meningkatkan Produktivitas Pekerja, Jurnal Engine: Energi, Manufaktur, dan Material, Vol. 3, No. 2, 2019: 66-72.

Rosnani Ginting, 2010. Perancangan Produk, Edisi Pertama, Graha Ilmu, Yogyakarta Buku.

Saufik Luthfianto, Siswiyanti, 2008. Pengujian Ergonomi Dalam Perancangan Desain Produk. Prosiding.

Saufik Luthfianto, Zulfah, Fajar Nurwildani, 2017. Perancangan Alat Penggiling Ikan Dengan Pendekatan Ergonomi Untuk Meningkatkan Produktifitas, Jurnal SIMETRIS, Vol 8 No 1 April 2017 : 1-8.

Steven D Eppinger, 2001, Perancangan dan Pengembangan Produk, Salemba Teknika, Jakarta. 
Tommy Dwi Putra, Perancangan Alat Pemotong dan Pembersih Usus Ayam Menggunakan Metode Benchmarking, Skripsi, Universtas Muhammadiyah Surakarta, 2018.

Tarwaka. Solichulha Bakri dan Lilik Sudiajeng. 2004. Ergonomi untuk keselamatan, kesehatan kerja dan produktivitas. Surakarta: UNIBA PRESS.

Wignjosoebroto Sritomo, 2000. Ergonomi, Studi Gerak dan Waktu, Guna Widya, Surabaya. 